\title{
The educational needs among obstetrical and gynecological nurses in El-Gharbia Governorate
}

\author{
Ghada Abd El-Salam Belal, Manal Abdalla Sayed Ahmed Gaheen, Fatma Abd Elrehim Mohamed* \\ Lecturer of Maternity and Gynecological Nursing Dept., Faculty of Nursing, Tanta University, Tanta, Egypt
}

Received: October 5, 2015

Accepted: November 29, $2015 \quad$ Online Published: December 21, 2015

DOI: $10.5430 /$ jnep.v6n4p84

URL: http://dx.doi.org/10.5430/jnep.v6n4p84

\begin{abstract}
Obstetrical and Gynecological nursing is a healthcare profession that focuses on the care of the women and newborn, for that reason Obstetrical and Gynecological nurses (OB/GYN nurses) should be highly knowledgeable and well trained caregivers for the overall safety and well-being of women from the moment of menarche to menopause. The aim of this study was to assess the educational needs among obstetrical and gynecological nurses in Gharbia Governorate. This study followed a descriptive design. The study was carried out at Tanta University Hospital and Zifta General Hospital these were selected using multistage random sample technique. The subjects of the study consisted of all obstetrical and gynecological nurses working in the previously mentioned settings (151 nurses). A structured interview questionnaire sheet was designed to collect the required data regarding the study elements. It comprised questions about socio-demographic and practice, general health educational programs, specific health educational programs and the specific health training programs. The main results of this study revealed that the majority of the nurses (90.7\%) weren't attended any training courses in obstetrical and gynecological nursing. The results also illustrated that around one half of the studied nurses $(56.1 \%)$ had low need for general theoretical education courses. The results also illustrated that $73.2 \%, 56.2 \%$ of the nurses in the study had low need for specific theoretical education courses and clinical training courses, respectively. The study concluded that the main general theoretical educational needs among the nurses in the study were; infection control, medical terminology, and decision making skills. While, the specific theoretical educational needs included: common medications during labor, normal labor, and emergency obstetrical and gynecological nursing. Also, the top clinical training needs among the nurses in the study were insertion and removal of IUD, immediate care of newborn, pre and post-operative nursing management and CPR. The study recommended the development of a series of continuing in-service training programs based on the educational needs assessment.
\end{abstract}

Key Words: Obstetrical and gynecological, Nurses, Educational needs

\section{INTRODUCTION}

The Millennium Development Goal for maternal health (MDG-5) calls for a reduction in maternal mortality by twothirds by the year 2015. ${ }^{[1]}$ The estimates of maternal mortality suggest that 342,900 maternal deaths occurred worldwide in 2008 , and that a total of $99 \%$ of these deaths occurred in developing countries. ${ }^{[2]}$ Almost $80 \%$ of maternal deaths are due to direct obstetric causes including hemorrhage, infection, and complication of unsafe abortion, eclampsia and obstructed labor. For every woman who dies, many more women suffer from disease and disability at the height of their productivity and family responsibility. ${ }^{[3]}$

Over the last two decades, many health indicators have improved; while maternal mortality rates and ratios have re-

\footnotetext{
*Correspondence: Fatma Abd Elrehim Mohamed; Email: dr_fatma7521@yahoo.com; Address: Maternity and Gynecological Nursing Dept., Faculty of Nursing, Tanta University, Tanta, Egypt.
} 
mained stagnant. The causes are rooted in the absence of high level commitment in protecting women's health and in the unavailability of skilled health professionals to provide optimal care. ${ }^{[4,5]}$

The first step toward preventing maternal mortality and morbidity is for nurses to realize that improvements are necessary and that nurses can play an important role in this process. ${ }^{[6]}$ Obstetrical and gynecological nurses form the backbone of the health care system and are the main providers of maternal health care. They function in a variety of settings as caregivers, client advocates, researchers, case managers, and educators. Also, they act as consultants in their area of expertise, as well as serving as role models, and teachers of quality nursing care. Furthermore, they play a large role in helping women remain well so that they can enter a pregnancy in good health and maintain their health throughout life. ${ }^{[7,8]}$

Knowing that Obstetrical and Gynecological (OB/GYN) nurses have a lot of roles to fill and are the major contributors to the health care delivery system in the country, therefore, providing an educational needs assessment should be considered by training planners as one of the important strategies to assist in planning better educational programs for them, and providing also better understanding of the requirement to address the many unique needs of women. ${ }^{[9-11]}$

\section{Aim of the study}

The present study aimed to assess the educational needs among obstetrical and gynecological nurses in El-Gharbia Government.

\section{METHOD}

\subsection{Design}

A descriptive design was used.

\subsection{Setting}

The study was conducted at Tanta University Hospital and Zifta General Hospital. They were selected using multistage random sample technique. El-Gharbia Governorate contains eight districts; four districts represented Agricultural areas and four districts represented Industrial areas. One center was randomly selected from each area. Tanta was randomly selected to represent the industrial area and Zifta was randomly selected to represent the agricultural area. Then Tanta University Hospital was randomly selected from Tanta city and Zifta General Hospital was randomly selected from Zifta.

\subsection{Subjects}

The study subjects consisted of all obstetrical and gynecological nurses working in the previously mentioned settings at the time of data collection $(n=151), 110$ nurses in Tanta University Hospital and 41 nurses in Zifta General Hospital.

\subsection{Tools of the study}

A structured interview questionnaire sheet was designed to collect the required data regarding the study elements. It comprised four parts:

Part one: It included questions about socio-demographic and practice characteristics such as: age, level of education, residence, marital status, years of experience in general nursing, years of experience in obstetrical and gynecological nursing, previous educational courses in general nursing and in obstetrical and gynecological nursing specific and previous training courses in general nursing and in obstetrical and gynecological nursing specific.

Part two: It encompassed questions about OB/GYN nurses needs for general theoretical educational courses.

Part three: It comprised questions about OB/GYN nurses needs for specific theoretical educational courses.

Part four: It comprised questions about OB/GYN nurses needs for clinical training courses.

An official letter was directed from the Faculty of Nursing, Tanta University to the Committee of Nursing in Tanta in order to obtain their acceptance to collect necessary data from the selected settings. Then, the permission was obtained from the hospitals administrative authorities. The study tool was developed after reviewing the related literature.

Validation of the tool was assessed by presenting it to five experts from the faculty members in Nursing College, Tanta University, three members of obstetrics and gynecology nursing, and two members from Community Health Nursing and Medical Surgical Nursing. The experts were asked to evaluate tools relevance and appropriateness on 4 point rating scales as: $1=$ not relevant, $2=$ little relevant, $3=$ relevant and 4 = very relevant. Opinions' of the experts on tools of study were analyzed and determined the following; face validity $95.28 \%$, content validity index (CVI) $100 \%$, and internal consistency reliability (coefficient alpha) was applied ( $\alpha=$ $0.91)$.

A pilot study was carried out on $10 \%$ of the study samples who were selected to evaluate the clarity and applicability of the research tool. They were excluded from the total sample, and necessary modifications were done based on their responses.

Informed consent was obtained from each studied participant included in the study. The anonymity and confidentiality of responses, voluntary participation and right to refuse to 
participate in the study were emphasized. The researchers explained the aim of the study to the participant by written explanation on the covering letter of the questionnaire. The Questionnaire was collected through structured interview; the researchers explained the questionnaire to the subjects and then, asked them to complete it. Data were collected by the researchers during the period from March to April 2014.

\subsection{Statistical analysis}

Data was collected, coded and organized into tables, and then analyzed using the statistical package for social science (SPSS version 17). Descriptive measures, including frequency, percentage, arithmetic mean and standard deviation were presented. ANOVA test were used for statistical correlation. $P$ values of $<.05$ were considered statistically significant.

\section{RESULTS}

Table 1 presents the distribution of the nurses in the study according to their socieo-demographic characteristics. It was found that among the nurses in the study $51.7 \%$ of them were $30-45$ years old, $74.8 \%$ of them had secondary technical nursing diploma in nursing, $57.6 \%$ of them were from urban areas, and $87.4 \%$ of them were married.

Figure 1 shows the distribution of the nurses in the study according to their years of experience in obstetric and gynecological nursing field. It was found that the majority (73.9\%) of the nurses in the study had from 10-20 years.

Table 1. Distribution of the nurses in the study according to their socieo-demographic characteristics

\begin{tabular}{|c|c|c|c|c|}
\hline \multirow{2}{*}{ Social-demographic characteristics } & \multicolumn{2}{|c|}{ The nurses in the study $(\mathrm{N}=151)$} & \multirow{2}{*}{$\chi^{2}$} & \multirow{2}{*}{$\boldsymbol{P}$} \\
\hline & No & $\%$ & & \\
\hline \multicolumn{5}{|l|}{ Age (in years) } \\
\hline Less than 30 & 34 & 22.5 & \multirow{4}{*}{6.45} & \multirow{4}{*}{$.005^{*}$} \\
\hline $30-45$ & 78 & 51.7 & & \\
\hline More than 45 & 39 & 25.8 & & \\
\hline Rang & $21-58$ & & & \\
\hline \multicolumn{3}{|l|}{ Level of education } & \multirow{5}{*}{7.25} & \multirow{5}{*}{$.001^{*}$} \\
\hline Secondary technical nursing diploma & 113 & 74.8 & & \\
\hline Technical Institute of Nursing & 20 & 13.2 & & \\
\hline Bachelor’s degree in nursing & 7 & 4.6 & & \\
\hline Diploma in the field of specialization & 11 & 7.4 & & \\
\hline \multicolumn{3}{|l|}{ Residence } & \multirow{2}{*}{4.25} & \multirow{2}{*}{$.001^{*}$} \\
\hline Urban & 87 & 57.6 & & \\
\hline \multicolumn{3}{|l|}{ Marital status } & \multirow{5}{*}{1.142} & \multirow{5}{*}{.285} \\
\hline Single & 12 & 7.9 & & \\
\hline Married & 132 & 87.4 & & \\
\hline Widow & 5 & 3.3 & & \\
\hline Divorced & 2 & 1.3 & & \\
\hline
\end{tabular}

* Significant or $P<.05$

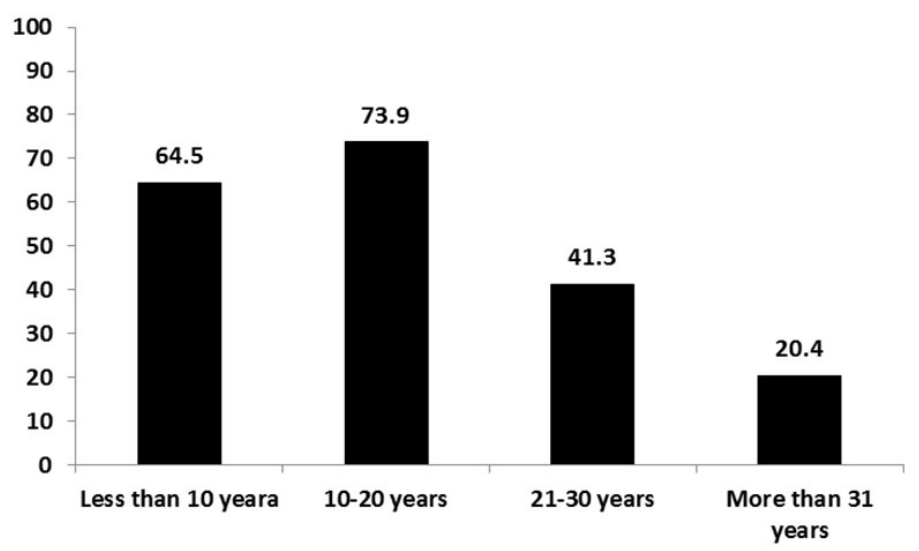

Figure 1. Distribution of the nurses in the study according to their years of experience in obstetric and gynecological nursing field 
Table 2 presents the distribution of the nurses in the study according to their previous training courses. It was noticed that $90.7 \%$ of the nurses in the study weren't attended any training courses in obstetrical and gynecological nursing.
Out of those who had taken courses, $64.3 \%$ of them had taken a course of infection control in obstetric. Also, the table showed that all the nurses in the study attended training courses only one time.

Table 2. Distribution of the nurses in the study according to their previous training courses

\begin{tabular}{lll}
\hline \multirow{2}{*}{ Previous training courses } & \multicolumn{2}{l}{ The nurses in the study (N = 151) } \\
\cline { 2 - 3 } & No & \% \\
\hline Attendance of training courses in obstetrical and gynecological nursing & & 9.3 \\
$\quad$ Yes & 14 & 90.7 \\
No & 137 & 64.3 \\
If yes, course's name & $\mathbf{( N = 1 4 )}$ & 28.6 \\
Infection control in obstetric & 9 & 7.1 \\
Health education about nursing care in obstetric & 4 & 100.0 \\
F.P methods & 1 & 0.0 \\
Frequency & & 0.0 \\
Once & 14 & 0 \\
Twice & 0 & \\
Three times & 0 & \\
\hline
\end{tabular}

Figure 2 shows the distribution of the nurses in the study according to their need for general theoretical education courses. It was noticed that $88.9 \%, 81.1 \%$ and $71.3 \%$, respectively, of the nurses in the study needed infection control, medical terminology and decision making skills courses, respectively.

Figure 3 presents the distribution of the nurses in the study according to their total need for general theoretical education courses. It was noticed that around one half of the nurses in the study $56.1 \%$ had low need for general theoretical educa- tion courses.

Figure 4 presents the distribution of the nurses in the study according to their total need for specific theoretical education courses. It was noticed that about three quarters (73.2\%) of the nurses in the study had low need for specific theoretical education courses.

Figure 5 presents the distribution of the nurses in the study according to their total need for clinical training courses. It was noticed that about more than one half $(56.2 \%)$ of the nurses in the study had low need for clinical training courses.

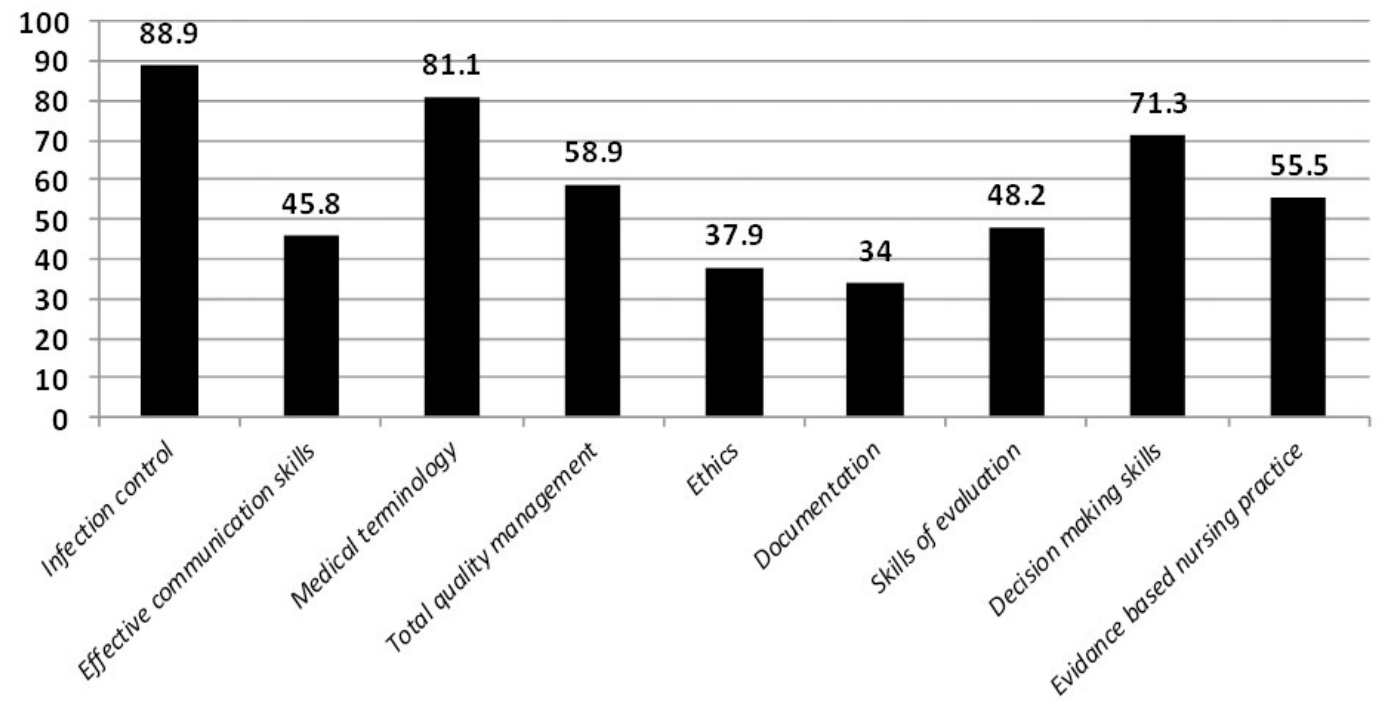

Figure 2. Distribution of the nurses in the study according to their need for general theoretical 


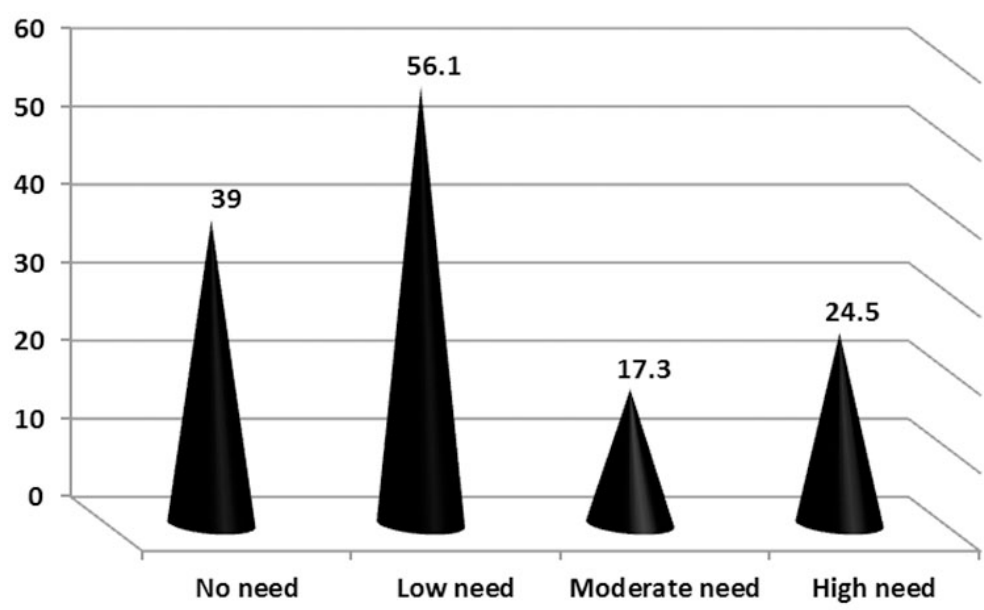

Figure 3. Distribution of the nurses in the study according to their total need for general theoretical education courses

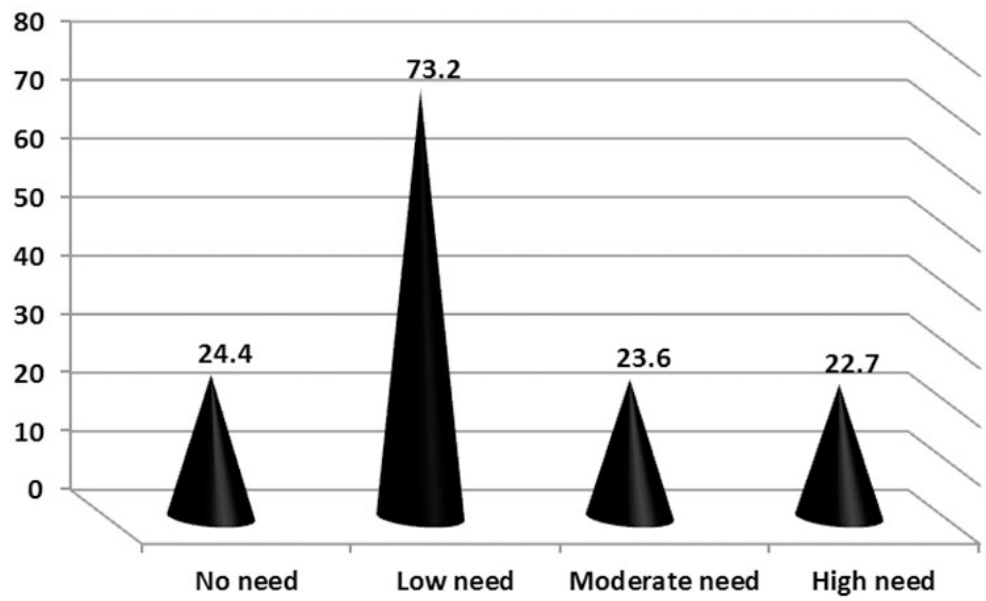

Figure 4. Distribution of the nurses in the study according to their total need for specific theoretical education courses

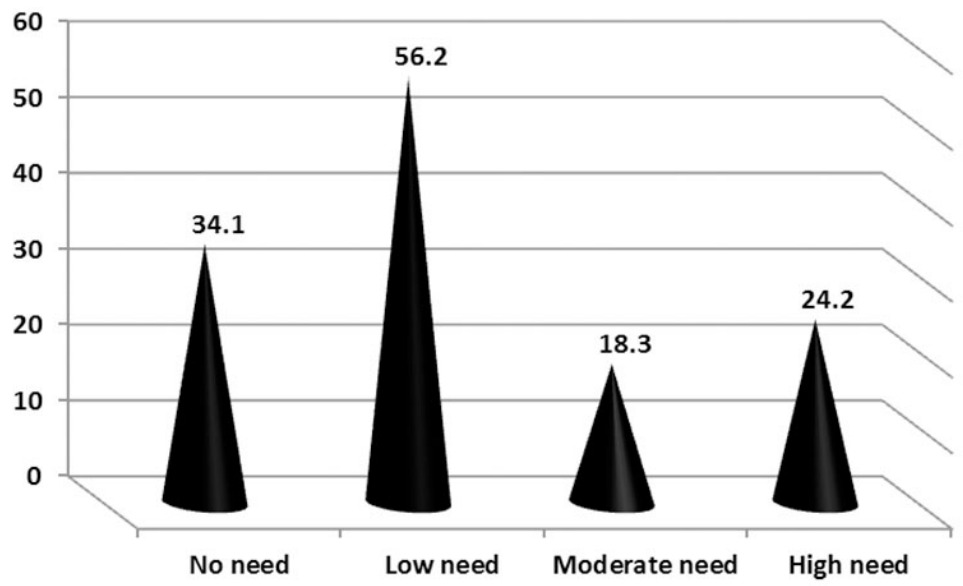

Figure 5. Distribution of the nurses in the study according to their total need for clinical training courses

Figure 6 presents the distribution of the nurses in the study according to the factors affecting their participation in training courses. It was noticed that the $98 \%$ of the nurses in the study mentioned that absence of continues evaluation and lack of support from hospital were the main factors affecting their participation in training courses, respectively. 


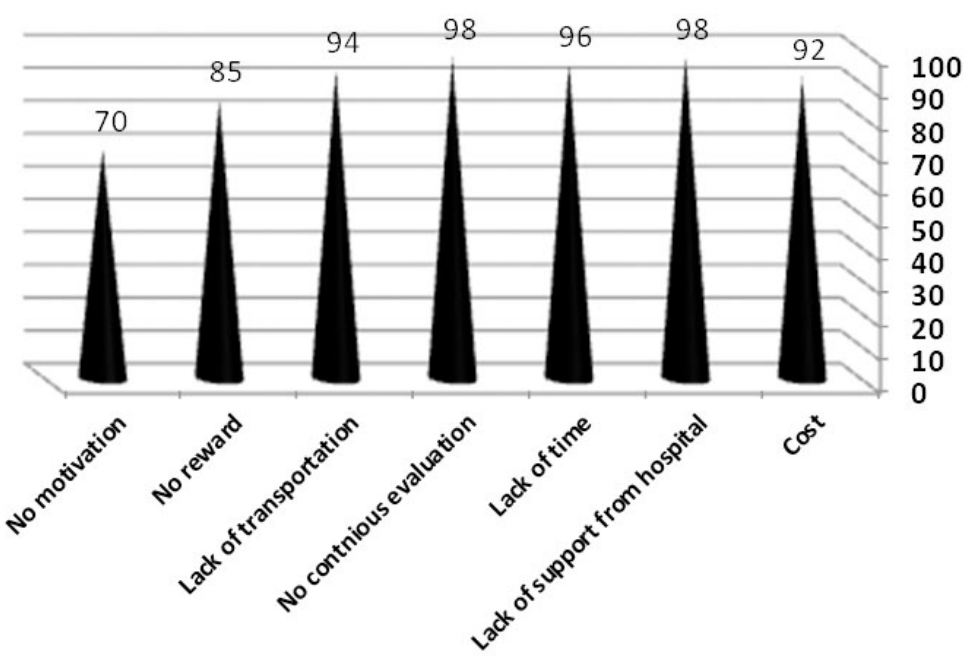

Figure 6. Distribution of the nurses in the study according to the factors affecting their participation in training courses

\section{Discussion}

Obstetrical and Gynecological nursing is a healthcare profession that focuses on the care of the women and newborn, for that reason OB/GYN nurses should be highly knowledgeable and well trained caregivers for the overall safety and wellbeing of women from the moment of menarche to menopause. Building knowledge and educational skills is considered as a powerful tool for personal performance improvement and to maintain the efficiency of any health care organization. A few studies have examined training needs analysis for OB/GYN nurses, ${ }^{[12-14]}$ so the present study aimed to assess the theoretical education and training needs of OB/GYN nurses in El-Gharbia Governorate prior to providing training courses for them. The result of the present study revealed that more than seventy percent of OB/GYN nurses in El-Gharbia Governorate had secondary technical nursing diploma and not specialized in obstetrics. These result contradicted with United State (US) roles which impose that the nurses must complete the education requirements to work as a registered nurse before beginning specialized in obstetrics. ${ }^{[15]}$

For the purpose of this study the needs assessment was divided into three educational needs: general theoretical; specific theoretical; and clinical training educational needs. As regard to the general theoretical educational needs, the present study revealed that the study subjects at El-Gharbia Governorate required continuing education as follows: infection control; medical terminology; and decision making skills. As regard to infection control this result agrees with several results, which demonstrated that there is a need for education interventions in the field of infection control for health care workers in most OB/GYN settings, particularly among nurses. ${ }^{[16-18]}$ While, there need for medical terminology was expected because more than half of the subjects in the present study had more than 10 years of experience and they didn't attend any courses about it. Also, because learning medical terminology is vital to communicating with other medical professionals. As regard to the study subjects' educational need for decision making skills, it is clear that the study subjects have the potential for participating in decision making. This result agrees with Gillespie and Paterson (2009), who recommended that a greater recognition of the potential for teaching decision making skills in basic and continuing education is needed. ${ }^{[19]}$

According to the specific theoretical educational needs, the present study indicated that the study subjects required continuing education were to know more about: common medications during labor, emergency obstetrical and gynecological nursing; and normal labor, physiology of conception, fertilization, implantation and fetal development. The specific theoretical educational needs among the study subjects reflect their needs for basic information on obstetrical nursing. As evidence-based practices promote normal birth, and $\mathrm{OB} / \mathrm{GYN}$ nurses are in a unique position to help childbearing women make informed choices based on evidence. ${ }^{[20]}$ While, as regard to the study subject's educational need for emergency obstetric management, this result agrees with Kavitta et al. (2014), they highlighted the need for improvement of knowledge on emergency obstetric management to protect the well-being of both mother and child. ${ }^{[21]}$

Regarding the clinical training needs, the present study revealed that the study subjects needs for clinical training issues regarding: insertion and removal of IUD, pre and postoperative nursing management. CPR, immediate care of the newborn, insertion and removal of IUD and episiotomy. These different needs for clinical training in the present study focused on patient-care-related needs at work. Because in- 
formation seeking either was routine and task oriented or was triggered by patient needs. These results agrees with several results which indicated that, although the importance of clinical teaching is universally acknowledge in the profession, little formal training is offered to prepare practitioners for this important role, and clinical practice setting that encourage teaching and learning can be powerful in educating both the existing nursing workforce and nursing students. ${ }^{[22,23]}$

It is obvious from the present study that the nurses needs for theoretical knowledge and training skills were low. These results disagree with Hennessy et al. (2006), who assess the training and development needs of nurses in Indonesia. They found that all nurses reported significant training needs for all 40 tasks. ${ }^{[24]}$ Also, these results disagree with Jones (2008), about training needs of nurses working in child and adolescent services. He found that training needs varied depending on the career trajectory of nurses, and where nurses were working. ${ }^{[14]}$

In the current study there was a positive correlation between the age and the years of experience of the studied nurses in El-Gharbia Governorate and their total needs regarding the general theoretical education, specific theoretical education and training courses. This may be due to the fact that young nurses during their reproductive age were busy by children and home, and they neglect to find information especially when there is no follow-up from the hospital. So, older and more experienced nurses, because of the responsibilities they have, should have adequate and update knowledge about their own responsibilities, be aware of all rules that have changed, and be accountable to the system. As a result, they are more likely to feel the need to participate in courses to update their information. The result of Ayyash and Aljeesh's study (2011), confirm the results of the current study. ${ }^{[25]}$

The results of the present study demonstrated that the majority of nurses at El-Gharbia Governorate had no previous

\section{REFERENCES}

[1] Sachs JD, McArthut JW. The Millennium Project: A plan for meeting the Millennium Development. Lancet. 2005; 365: 347-53. http://dx.doi.org/10.1016/S0140-6736(05)70201-4

[2] Bhutta ZA, Chopra M, Axelson H, et al. Countdown to 2015 decade report (2000-10): Taking stock of maternal, newborn, and child survival. Lancet. 2010; 375: 2032-44. http://dx.doi .org/10.1016 /S0140-6736(10)60678-2

[3] Ndola P, Paige P, Amita S, et al. Maternal mortality in developing countries: challenges in scaling-up priority interventions. Women's Health. 2010; 6(2): 311-27.

[4] Raoa C, Shetty P. Evaluative Study on Effectiveness of Mater- training courses in Obstetric and Gynecological Nursing, the nurses turn the reason to the lack of continuous evaluation, lack of support from the hospital, lake of transportation and lack of financial resources. The result of Samad (2005) and Saeki et al. (2007), confirm the present study results. ${ }^{[26,27]}$ While, according to the result of the present study, motivation was the lowest percent factor influencing the nurses' participation in training courses. This result disagrees with several results, which indicated that motivation is one of the main factors affecting the employees' participation in training programs. ${ }^{[10,28,29]}$

\section{Limitations}

For this study, there was no previous published educational need assessment for nurses in El-Gharbia Government or in Egypt and these reduced the number of article included in this review on the national level.

\section{Conclusion}

The main general theoretical educational needs among the study subjects were; infection control, medical terminology, and decision making skills. While, the specific theoretical educational needs included: common medications during labor, normal labor, and emergency obstetrical and gynecological nursing. Also, the top clinical training needs among the study subjects were: insertion and removal of IUD, immediate care of newborn, pre and post-operative nursing management and CPR.

\section{Recommendations}

The study recommended the development of a series of continuing in-service training programs based on the educational needs assessment, and the replication of the study in other setting before providing any educational program.

\section{CONFlicts OF INTEREST Disclosure}

The authors declare that there is no conflict of interest. nal and Child Health Care Participatory Training Program among Staff Nurses, Auxiliary Nurse Midwives and Lady Health Visitors. J South Asian Feder Obst Gynae. 2012; 4(2): 120-22. http: //dx.doi.org/10.5005/jp-journals-10006-1191

[5] Mojekwu J, Ibekwe U. Maternal Mortality in Nigeria: Examination of Intervention Methods, International Journal of Humanities and Social Science. 2012; 2(20): 135.

[6] Gillman J. Leading Nursing Journal Explores How Nurses Can Eliminate Preventable Hemorrhage-related Maternal Morbidity, Association of Women's. Obstetric and Neonatal Nurses. 2012.

[7] Rizzuto R, Rashid S. Skilled Care during Childbirth: Country Profiles, Family Care International. 2002. 
[8] Pillitteri A. Maternal and Child Health Nursing: Care of the Childbearing and Childrearing Family, 6thed. Philadelphia: Lippincott Williams \& Wilkins. 2009; 10-25.

[9] Lambert V, Daly J, Kunaviktikul W, et al. Nursing Education on Women's Health Care in Australia, Japan, South Korea, and Thailand. Journal of Transcultural Nursing. 2004; 15(1): 4453. PMid:14768415 http://dx.doi.org/10.1177/104365960 3259973

[10] Sajjadnia Z, Sadeghi A, Kavosi Z, et al. Factors affecting the nurses' motivation for participating in the in-service training courses: A case study. J Health Man \& Info. 2015; 2(1): 21-26. http: $/ / \mathrm{dx}$.doi.org/10.3855/jidc.526

[11] Mohammadi MA, Dadkhah B. Continuous Medical Education from View of Nursing Personnel Working in Ardabil Hospitals. Journal of Ardabil University of Medical Sciences. 2005; 5(3): 271-277.

[12] Mousavi A, Haghighi S, Sharafifar F. Program evaluation of nursing continuing education credit for nurses hospitals affiliated to Ahvaz University of Medical Sciences in 2006. National Conference on Education in Nursing. Zanjan. 2006.

[13] Bee F, Bee R. Learning needs analysis and evaluation, 2nd ed., London: Chartered Institute of Personnel and Development. 2003.

[14] Jones L. Health Service Executive. Report of nursing and midwifery education review group. Changing practice to support service delivery, office of the nursing services director. 2008. Available from: http//www.midwifery/group/mid.nur

[15] Kelchner L, Media D. What Kind of Schooling Is Needed to Be an Obstetrics Nurse? 2013.

[16] Hassan A, Moftah F, Alaa El-Din S, et al. Assessment of An Educational Training Program for Nurses Working in Maternal and Child Health (MCH) Centers in Assuit City Regarding Infection Control. Ass. Univ. Bull. Environ. Res. 2004; 7(2): 91-105.

[17] Butsashvili M, Kamkamize G, Umikashvili L, et al. Knowledge of Health care-associated infections among Georgian obstetricians and gynecologists. J Infect Dev Ctries. 2010; 4(5): 329-333.

[18] Sari S, Ibrahim K, Haroen H, et al. Knowledge, attitude and perceived adherence with universal precautions among health care workers in the obstetrics and gynecology department of an Indonesian teaching hospital. Int J Infect Control. 2011; 7: 14. http: //dx.doi.org/10.3396/ijic.V7i4.036.11
[19] Gillespie M, Paterson B. Helping Novice Nurses Make Effective Clinical Decisions: The Situated Clinical Decision-Making Framework. 2009; 30(3): 164-70.

[20] Romano A, Lothian J. Promoting, Protecting, and Supporting Normal Birth: A Look at the Evidence. JOGNN. 2008; 37: 94105. PMid:18226163 http://dx.doi.org/10.1111/j.1552-6 909.2007.00210.x

[21] Kavitha P, Tesfay A, Prasath A, et al. To assess level of knowledge of staff nurse on emergency obstetric management at orotta national referral maternity hospital. IJAMSCR. 2014; 2(4): 287-293.

[22] Raisler J, O'Grady M, Lori J. Clinical Teaching and Learning in Midwifery and Women's Health. J Midwifery Women Health 2003; 48(6): 398-406. http://dx.doi.org/10.1016/S1526-9 523(03) 00304-0

[23] Henderson A, Briggs J, Schoonbeek S, et al. A framework to develop a clinical learning culture in health facilities: Ideas from the literature. International Nursing Review. 2011; 58: 196-202. PMid:21554293 http://dx.doi.org/10.1111/j.1466-7657.2010.00858.x

[24] Hennessy D, Hicks C, Hilan A, et al. The training and development needs of nurses in Indonesia. Human Resources for Health. 2006; 4: 10. PMid:16630363 http://dx. doi .org/10.1186/147 8-4491-4-10

[25] Ayyash H, Aljeesh Y. Nurses' Motivation and their Performance at European Gaza Hospital in Gaza Strip. Journal of Al Azhar University - Gaza (Natural Sciences). 2011; 13: 55-68.

[26] Samad S. Unraveling the organizational commitment and job performance relationship. The Business Review. 2005; 4(2): 79-84.

[27] Saeki K, Lzumi H, Uza M, et al. Factors associated with the professional competencies of public health nurses employed by local government agencies in Japan. Public Health Nursing. 2007; 24(5): 149-57. PMid:17714229 http://dx.doi.org/10.1111/j $.1525-1446.2007 .00655 . x$

[28] Ebadi A, Amerioun A, Tavakkoli H, et al. Survey of related factors with motivation of nurses intend to participating in the in-service training in affiliated baqiyatallah university hospitals in 2010. Iranian Journal of Nursing Research. 2012; 6(23): 32-40.

[29] Flores PY, Alonso CM. Factors influencing nursing staff members' participation in continuing education. Revista Latino-American Enermahem. 2006; 14(3): 309-315. http://dx.doi.org/10.1590/s 0104-11692006000300002 